\title{
Article \\ Ionic Liquids for the Selective Solvent Extraction of Lithium from Aqueous Solutions: A Theoretical Selection Using COSMO-RS
}

\author{
Felipe Olea ${ }^{1}{ }^{1}$, Guillermo Durán ${ }^{1}$, Georgina Díaz ${ }^{1}$, Eduardo Villarroel ${ }^{1}$, Claudio Araya-López ${ }^{2}$, Rene Cabezas ${ }^{3}$, \\ Gastón Merlet $^{4}{ }^{\oplus}$, Julio Romero ${ }^{2}$ and Esteban Quijada-Maldonado ${ }^{1, *}$ \\ 1 Laboratory of Separation Processes Intensification (SPI), Department of Chemical Engineering, \\ University of Santiago de Chile, Av. Lib. Bdo. O’Higgins 3363, Estación Central, Santiago 9170020, Chile; \\ felipe.oleac@usach.cl (F.O.); guillermo.duran@usach.cl (G.D.); georgina.diaz@usach.cl (G.D.); \\ eduardo.villarroel@usach.cl (E.V.) \\ 2 Laboratory of Membrane Separation Processes (LabProSeM), Department of Chemical Engineering, \\ University of Santiago de Chile, Av. Lib. Bdo. O’Higgins 3363, Estación Central, Santiago 9170020, Chile; \\ claudio.arayal@usach.cl (C.A.-L.); julio.romero@usach.cl (J.R.) \\ 3 Departamento de Química Ambiental, Facultad de Ciencias, Universidad Católica de la Santísima Concepción, \\ Concepción 4090541, Chile; rene.cabezas@ucsc.cl \\ 4 Departamento de Agroindustrias, Facultad de Ingeniería Agrícola, Universidad de Concepción, \\ Vicente Méndez 595, Chillán 3812120, Chile; gmerlet@udec.cl \\ * Correspondence: esteban.quijada@usach.cl; Tel.: +56-2-718-18-38
}

\section{check for}

updates

Citation: Olea, F.; Durán, G.; Díaz, G.; Villarroel, E.; Araya-López, C.;

Cabezas, R.; Merlet, G.; Romero, J.; Quijada-Maldonado, E. Ionic Liquids for the Selective Solvent Extraction of Lithium from Aqueous Solutions: A

Theoretical Selection Using COSMO-RS. Minerals 2022, 12, 190. https://doi.org/10.3390/ $\min 12020190$

Academic Editor: Hyunjung Kim

Received: 11 December 2021

Accepted: 28 January 2022

Published: 31 January 2022

Publisher's Note: MDPI stays neutral with regard to jurisdictional claims in published maps and institutional affiliations.

Copyright: (C) 2022 by the authors. Licensee MDPI, Basel, Switzerland. This article is an open access article distributed under the terms and conditions of the Creative Commons Attribution (CC BY) license (https:// creativecommons.org/licenses/by/ $4.0 /)$.

\begin{abstract}
In this study, the theoretical design of ionic liquids (ILs) for predicting selective extraction of lithium from brines has been conducted using COSMO-RS. A theoretical model for the solvent extraction (SX) of the metal species present in brines was established considering extraction stoichiometry, the distribution of the extractants between aqueous and IL phases, and IL dissociation in the aqueous phase. Theoretical results were validated using experimental extraction percentages from previous works. Results indicate that, in general, the theoretical results for lithium extraction follow experimental trends, except from magnesium extraction. Finally, based on the model, an IL was proposed that was based on the phosphonium cation as the extractant, along with the phase modifier tributylphosphate (TBP) in an organic diluent in order to improve selectivity for lithium extraction over sodium. These results provide an insight for the application of ILs in lithium processing, avoiding the long purification times reported in the conventional process.
\end{abstract}

Keywords: solvent extraction; ionic liquids; lithium; selectivity

\section{Introduction}

At present, lithium ( $\mathrm{Li}$ ) is one of the most strategic and essential elements for technological development and for achieving $\mathrm{CO}_{2}$ neutrality by 2050. This is due to the high charge-to-weight ratio exhibited by this metal in the manufacturing of lithium-ion batteries $\left(\mathrm{Li}_{1-\mathrm{x}-\mathrm{y}} \mathrm{Mn}_{\mathrm{x}} \mathrm{Co}_{\mathrm{y}} \mathrm{O}_{2}\right)$, which are used to power smart devices and electric vehicles. Therefore, an increase in the demand for this metal is expected in the coming years [1,2]. More than half of the world's lithium deposits as brine water are located in the triangle of South America, which comprises Chile, Bolivia, and Argentina [3,4].

The processing of lithium resources presents challenges that have to be solved, and the complexity of extraction and purification of this mineral depends on its source. Brine is the principal source of lithium [5], but its extraction and separation are tedious because these processes require a solar evaporation step to concentrate the mineral, which results in long processing times ranging from six to eighteen months. Subsequently, magnesium, calcium, and boron are removed in several stages of precipitation using sodium carbonate and lime [6]. In addition to this, large quantities of freshwater have to be injected into the lithium wells to pump off the brines, which causes water pollution, affecting the 
biodiversity of the environment and human health [7], not to mention the fact that water is extremely scarce in places where lithium is found [8].

In this sense, solvent extraction (SX) could be proposed as an alternative to the conventional process in order to avoid time-consuming processing and to considerably reduce water consumption. However, an important drawback is that the direct extraction of lithium from high concentration magnesium brines, which share similar physicochemical properties [9], would require a highly selective SX process.

To increase the separation factor between these two metals, the use of ionic liquids (ILs) appears to be a promising alternative. ILs are molten salts at room temperature, which have favorable physicochemical properties that make them suitable solvents for SX processes [10-12], for example, negligible vapor pressure. Additionally, ILs can increase the distribution ratios and selectivity of $\mathrm{Li}^{+} / \mathrm{Mg}^{2+}\left(\alpha_{\mathrm{Li}^{+}} / \mathrm{Mg}^{2+}\right)$ when compared to conventional solvents [13]. Furthermore, the use of a neutral donor (e.g., tributhyl phosphate (TBP); trioctyl phosphine oxide (TOPO) and triisobutyl phosphate (TIBP)) in combination with ILs could enhance extraction [14-17] or selectivity [18].

Shi et al. used two different non-fluorinated ILs with the anion bis(2-ethylhexyl)phosphate and different alkyl length in the ammonium $\left(\left[\mathrm{N}_{4444}\right]^{+}\right.$and $\left.\left[\mathrm{N}_{8888}\right]^{+}\right)$, achieving high extraction towards lithium over sodium, potassium, rubidium, and cesium [19]. In addition, $\mathrm{Li}$ et al. were able to separate lithium from magnesium $\left(\alpha_{\mathrm{Mg}^{2+} / \mathrm{Li}^{+}}=21.8\right)$ using a binary extractant composed of Aliquat 336 and Versatic Acid 10 [A336][V10], in which the extracting phase can be stripped and regenerated by water [20]. These two works show the feasibility of using direct SX without precipitation and concentration steps, which could improve the efficiency of lithium extraction from brines by SX.

In turn, ILs have many possible combinations of cations and anions that can be used to increase extraction and/or selectivity [21-23]. However, studying each of these combinations would be time consuming and require high experimental costs. In this sense, a quick tool for exploring these combinations is COSMO-RS (Conductor-like Screening Model for Real Solvent) [24], which has succeeded in the prediction of metal extraction with conventional organics solvents [25-27] and also with ILs as diluents [28]. For instance, Zhao et al. used COSMO-RS to predict the extraction of $\mathrm{LiCl}$ in different ILs [23]. However, the main problem of this approach is that lithium will be not extracted as a salt but the extraction mechanism would include the exchange of chloride anions for an anion of the IL. In fact, ILs are known to participate in the extraction of metal $[12,29,30]$, including the transfer of the IL ions from the organic phase to the aqueous phase. Therefore, to obtain good trends between experimental and theoretical results, the extraction stoichiometry and all the local thermodynamic equilibrium of the species involved in the complexation should be considered [28].

Therefore, the aim of this work is to establish a theoretical SX model to predict selective extraction of lithium over sodium and magnesium, which are present in brines, using different ILs as extractants by means of COSMO-RS. To this end, selectivity will be calculated based on the distribution constant of all species involved in extraction stoichiometry and free energy of complexation in the aqueous phase. Theoretical results will be compared with experimental data of extraction percentages and selectivity from lithium recovery. Finally, an IL that allows for increasing selectivity over the reported values from previous works is proposed.

\section{Model Development and Computation Procedure}

\subsection{Predictive Method for Selectivity Calculation}

According to our previous work [28], COSMO-RS is capable of calculating local equilibrium and the constants from the stoichiometry in the SX process. This allows for obtaining the theoretical selectivity between $\mathrm{Li}^{+}$and the other metals $\left(\mathrm{Na}^{+}\right.$and $\left.\mathrm{Mg}^{2+}\right)$ present in brines, considering an extracting phase composed of a synergistic agent and different hydrophobic ILs as extractants diluted in conventional organic solvents. In this 
thermodynamic model, the extraction stoichiometry of this metal with ILs and a neutral donor must be known, which could be summarized as follows.

$$
M_{(a q)}^{x+}+y N_{(\text {org })}+x C A_{(\text {org })} \leftrightarrow M A_{X} N_{y(\text { org })}+x C_{(a q)}^{+}
$$

For $\mathrm{Li}^{+}$extraction, the literature indicates that SX proceeds via cation exchange and solvation mechanisms $[12,31,32]$. Specifically, for each mole of lithium extracted, one mole of the anion $(A)$ of the IL $(C A)$ and two moles of a neutral donor $(N)$ are needed. The $\mathrm{Na}^{+}$cation exhibits almost the same ionic radii as lithium [33]; as a consequence, the coordination number will be related to this property, among other factors [34]. In turn, in the extraction stoichiometry of magnesium (Mg) with ILs, this metal ion is coordinated with two anions of IL [20,35] and two molecules of TBP [36]. Considering this, a general stoichiometry for different metals is obtained through Equation (2).

$$
M^{x+} C l_{n(a q)}+2 T B P_{(\text {org })}+x C A_{(\text {org })} \leftrightarrow M^{x+} A_{x} \cdot 2 T B P_{(\text {org })}+x C C l_{(a q)}
$$

With $\mathrm{M}^{x+}=\mathrm{Li}^{+}, \mathrm{Na}^{+}, \mathrm{Mg}^{2+}$ and sub-indices $a q$ and org corresponding to the aqueous and organic phase, respectively.

Figure 1 summarizes SX stoichiometry and the steps involved in the SX process, showing the path followed by the extractant IL $(C A)$ when extracting metal ions $\left(M^{x+}\right)$ with a charge $(x)$ from aqueous solutions.

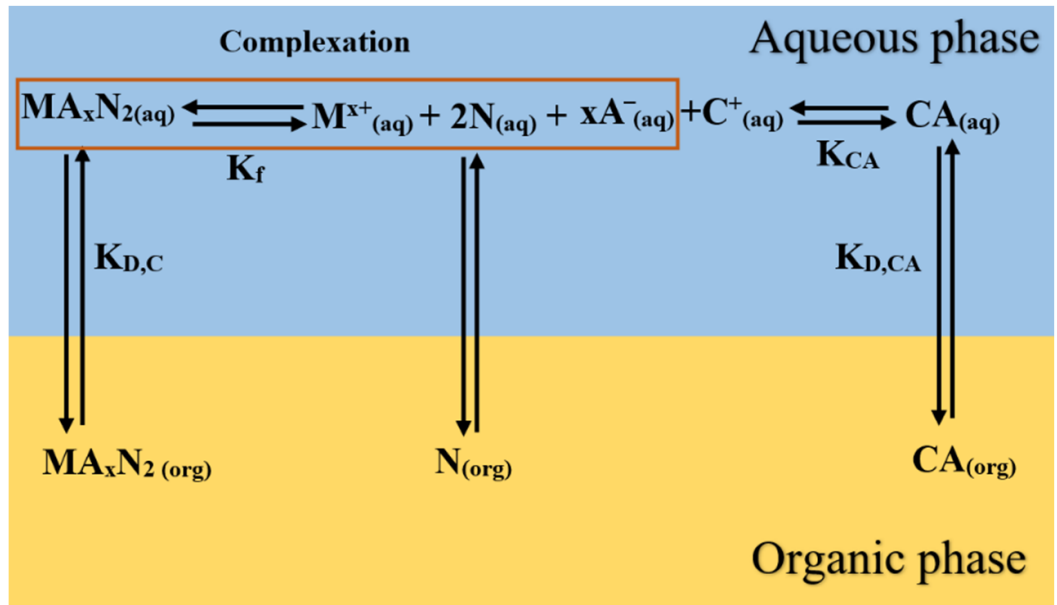

Figure 1. Proposed extraction path for the IL extractant and a neutral donor in the SX process of a certain metal.

In Figure 1, the IL extractant, which is initially present in the organic medium $\left(C A_{(\text {org })}\right)$, is transferred to the aqueous phase according to its distribution constant $\left(K_{D, C A}\right)$. Once there, it is solvated by water, dissociating to some extent into a cation $\left(\mathrm{C}_{(a q)}^{+}\right)$and into an anion $\left(A_{(a q)}^{-}\right)$according to their dissociation constant $\left(K_{C A}\right)$. The anion $A_{(a q)}^{-}$is responsible for extracting the metals from an aqueous solution, displacing chloride ions from lithium [37]. Additionally, the neutral donor is distributed between organic and the aqueous phases given by the distribution constant $\left(K_{D, N}\right)$.

Then, extraction is carried out, forming the $M^{x+} A_{x} N_{y(a q)}$ complex, for which its extraction constant is defined by $K_{f}$. Finally, the organometallic complex formed from the previous complexation dissolves into the organic phase according to the distribution constant $\left(K_{D, C}\right)$ between the aqueous and organic phases. All these equilibrium constants and distribution ratios are defined as follows by Equations (3)-(7).

$$
K_{D, C A}=\frac{[C A]_{(a q)}}{[C A]_{(o r g)}}
$$




$$
\begin{gathered}
K_{C A}=\frac{\left[C^{+}\right]_{(a q)}\left[A^{-}\right]_{(a q)}}{[C A]_{(a q)}} \\
K_{D, N}=\frac{[N]_{(a q)}}{[N]_{(o r g)}} \\
K_{f}=\frac{\left[M A_{x} N_{2}\right]_{(a q)}\left[C^{+}\right]_{(a q)}^{x}}{[\mathrm{M}]_{(a q)}^{x+}\left[A^{-}\right]_{(a q)}^{x}[N]_{(a q)}^{2}} \\
K_{D, C}=\frac{\left[M A_{x} N_{2}\right]_{(o r g)}}{\left[M A_{x} N_{2}\right]_{(a q)}}
\end{gathered}
$$

Based on the previous equations of local thermodynamic equilibrium, a global constant $\left(K_{\text {global }, i}\right)$ of each component " $i$ " (" $i$ " can be lithium, sodium, or magnesium) summarizes the global extraction process.

$$
K_{\text {global }, i}=K_{D, C A}^{x} K_{C A}^{x} K_{D, N}^{2} K_{f} K_{D, C}
$$

The algebraic arrangement of Equation (9) results in the expression for $K_{g l o b a l, i}$ is as follows.

$$
K_{\text {global }, i}=\frac{\left[M A_{x} N_{2}\right]_{(\text {org })}\left[C^{+}\right]_{(\text {aq })}^{x}}{\left[M^{x+}\right]_{(a q)}[C A]_{(\text {org })}^{x}[N]_{(\text {org })}^{2}}
$$

Finally, predicted selectivity is obtained by dividing the global constants of lithium vs the other metal in the following manner:

$$
S_{L i^{+} / M^{x+}}=\frac{K_{\text {global }, L i}}{K_{\text {global }, M^{x+}}}
$$

Equation (10) should be compared with experimentally obtained selectivity to validate this model.

In order to validate theoretical calculations and compare them with experimental data, experimental data were obtained from previous studies. To compare lithium extraction using ammonium-based IL, data were taken from the work of Zhao et al. [23], in which different cations and anions were used. Finally, to validate the $\mathrm{Li}^{+} / \mathrm{M}^{x+}$ selectivity trends, data were retrieved from Wang et al. using bis[(trifluoromethyl)sulfonyl]imide-based ILs [22].

\subsection{Computation Procedure}

The molecules of Equations (3)-(7) have to be optimized before being used in COSMORS. Molecular optimizations were carried out in Turbomole ${ }^{\circledR}$ (version 7.4., TURBOMOLE $\mathrm{GmbH}$, Karlsruhe, Germany) using a basis set with triple-zeta valence polarization (defTZVP) [38]. Density functional theory (DFT) with DGA functionality, Becke-Perdew (BP86), is widely used in organometallic complex optimization [39-42] with dispersion correction (D4), as suggested by Grimme et al. [43,44]. After geometry optimization, a vibrational frequencies analysis was performed in Turbomole ${ }^{\circledR}$ for every molecule in order to obtain the chemical potential and the absence of imaginary harmonic frequencies and ensure that all were stable molecules with zero negative frequencies. Subsequently, COSMO-RS calculations were conducted with these molecules using the COSMOTherm $X^{\circledR}$ (version C30_1705, COSMOlogic GmbH \& Co., Leverkusen, Germany) software.

In order to improve COSMO-RS calculations, the conformers of the ILs were considered searching rotatable bonds. To this end, a stochastic search algorithm at the MMX force field level of theory, which is implemented in the PCmodel software [45]. Only molecules with the lowest energy and not exceeding an energy threshold by more than $0.5 \mathrm{kcal} / \mathrm{mol}$ were reoptimized in Turbomole ${ }^{\circledR}$, and then the molecules with the lowest energy (potential chemical in vacuum + solvation free energy) were employed. 
Due to the impossibility of representing the cation $\mathrm{M}^{\mathrm{x}+}$ as an atom in quantum chemical calculations, this work considered solvated metals in an aqueous solution with water molecules. According to the literature, the number of water molecules in the inner and second coordination sphere of lithium and magnesium are six and twelve, respectively [46,47]; the use of the second solvation shell in the free metals is necessary to have good agreement with the experimental extraction results.

Equation (6) was calculated with a Born-Haber cycle $\left(\Delta G_{\text {complexation }}=\Delta G_{\text {vacuum }}+\right.$ $\left.\Delta G_{\text {Solvation }}\right)$. To this end, the chemical potential for every molecule in extraction stoichiometry was calculated based on a vibrational frequency analysis in Turbomole ${ }^{\circledR}$ and solvation energy in the aqueous media with COSMOTherm $X^{\circledR}$. The distribution partition between the aqueous and organic phase in Equations (3)-(5) and (7), is obtained considering the solutes at infinite dilution in both phases, using the panel $\log \mathrm{P} / \log \mathrm{D}$ in $\operatorname{COSMOTherm} \mathrm{X}^{\circledR}$. In the organic phase, an electroneutral mixture was considered for IL.

\section{Results and Discussion}

This study is divided into two main parts: the first one deals with the comparison of our model to predict extraction and selectivity with experimental data, while the second one part is a proposal for ILs that achieves selectivity.

\subsection{Effect of IL Anion on The Extraction of Lithium}

The comparison between COSMO-RS calculations and experimental data for SX of lithium [23] is carried out with ILs Tetrabutylammonium mono-2-ethylhexyl-(2-ethylhexyl) phosphonate [EHPMEH] $\left[\mathrm{N}_{4444}\right]$; Tetrabutylammonium bis(2-ethylhexyl)phosphate [DEHP][N $\left.\mathrm{N}_{444}\right]$; Tetrabutylammonium bis(2-ethylhexyl)phosphinate [BEHP][N $\left.\mathrm{N}_{4444}\right]$; and Tetrabutylammonium diisooctylphosphinate [DICP][N $\left.\mathrm{N}_{444}\right]$, while the cations and anion used are shown in Figure 2. Experimental concentrations used in the work of Zhao et al. [23] are of $0.5(\mathrm{~g} / \mathrm{L}) \mathrm{Li}^{+}$aqueous phase and an organic phase containing 0.1 (mol/L) of IL diluted in methylbenzene at $298 \mathrm{~K}$.

(a)<smiles>CCCCCCCC(CC)CC(CC)(CC)OP(=O)([O-])[O-]</smiles>

(b)

(c)<smiles>CCC(CC)CP(=O)([O-])CC(CC)CC</smiles>

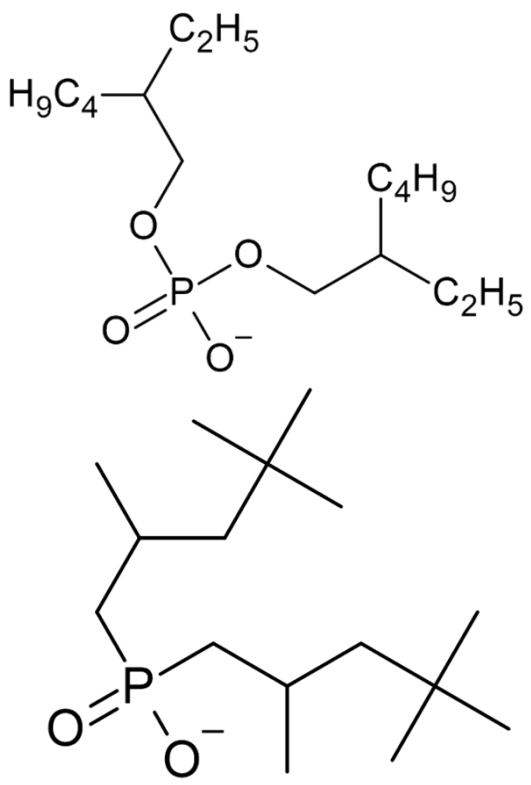

Figure 2. Cont. 
(e)<smiles>[14CH3]C([O-])O</smiles>

$(\mathrm{g})$ (f)<smiles>CCC(C)(C)[N+](C)(C)C</smiles>

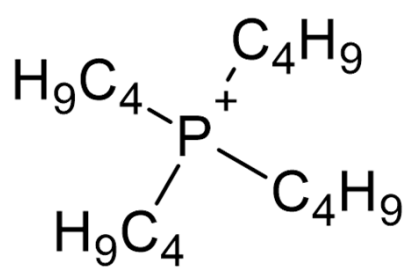

Figure 2. Molecular structure of the anions and cation used: (a) [EHPMEH], (b) [DEHP], (c) [BEHP], (d) $[\mathrm{DICP}],(\mathbf{e})[\mathrm{C} 11 \mathrm{O}],(\mathbf{f})\left[\mathrm{N}_{4444}\right]$ and $(\mathrm{g})\left[\mathrm{P}_{4444}\right]$.

Table 1 compares the results calculated by COSMO-RS (Log (K $\left.\mathrm{K}_{\text {global }}\right)$, Equation (9)) and the experimental extraction percentages obtained from the work of Zhao et al. [23]. According to the results presented in Table 1, COSMO-RS calculations can predict experimental trends when compared to the experimental data available. Nevertheless, an explicit solvation model could be used to improve the results, but for prior screening, the results show a good tendency.

Table 1. COSMO-RS and experimental [23] calculations for lithium extraction.

\begin{tabular}{ccc}
\hline IL & Log $\left(\mathbf{K}_{\text {global }}\right)$ & $\% \mathbf{~}$ \\
\hline$\left[\mathrm{N}_{4444}\right][\mathrm{EHPMEH}]$ & 216.50 & 34.6 \\
{$\left[\mathrm{~N}_{4444}\right][\mathrm{DEHP}]$} & 220.22 & 24.9 \\
{$\left[\mathrm{~N}_{4444}\right][\mathrm{BEHP}]$} & 219.14 & 6.6 \\
{$\left[\mathrm{~N}_{4444}\right][\mathrm{DICP}]$} & 219.05 & 6.1 \\
{$\left[P_{4444}\right][\mathrm{DEHP}]$} & 219.98 & 21.8 \\
{$\left[P_{4444}\right]\left[\mathrm{C}_{11} \mathrm{O}\right]$} & 217.42 & 11.7 \\
\hline
\end{tabular}

As observed in Table 1, the experimental results were sorted by maintaining the IL cation and varying the anion in ILs screening. It is shown that the main factor that would increase or decrease lithium extraction/selectivity is the IL anion because this is directly involved in lithium bonding. Additionally, the change in chemical structure will affect energy bonding as this energy will be related to the charge density in the bonding acceptors atoms that are present in the anion, specifically in the $\mathrm{P}=\mathrm{O}$ group; in this group, the charge density will be affected by the radicals present in the vicinity of the bonding.

Therefore, according to the experimental results, the higher the number of oxygen bonding the phosphorus atom in the IL anion, the better the lithium extraction. This is due to the electron withdrawing effect of oxygen, which provides a higher density charge in $\mathrm{P}=\mathrm{O}$ and, thus, a better bonding with lithium. The introduction of carbon molecules bonded to phosphorus reduces both the bonding interaction due to its electron donating character and the negative density charge area. However, in SX, the effect of the polarity of the extractant is not the only effect to be considered, as shown in our model (see Figure 1). Furthermore, the dissociation of IL has to be taken into account and this can be represented by the $\sigma$-profiles of the extractant anions.

In Figure 3, the $\sigma$-profiles of the anions used are presented. The region within -1 and $1\left(\mathrm{e} / \mathrm{A}^{2}\right)$ corresponds to a non-polar region, while the outside corresponds to the ability to form hydrogen bonds. The central peaks located in the -0.6 to $0.5\left(\mathrm{e} / \mathrm{A}^{2}\right)$ region show the non-polar zone of this anion, while the small peaks located near the value of $2\left(\mathrm{e} / \mathrm{A}^{2}\right)$ indicate the polar region of the anions. Therefore, the more to the right the peak is located in the $\sigma$-profile, the more polar the anion is; therefore, the Coulombic forces 
between the cation and the anion of the IL will increase. This effect hinders the dissociation of IL in the aqueous phase, decreasing the amount of anions available for extraction. Thus, [EHPMEH] $^{-}$and [DEHP] $]^{-}$anions present peaks around 2.1 and $2.3\left(\mathrm{e} / \mathrm{A}^{2}\right)$, respectively, presenting the highest dissociations among the IL used in this work.

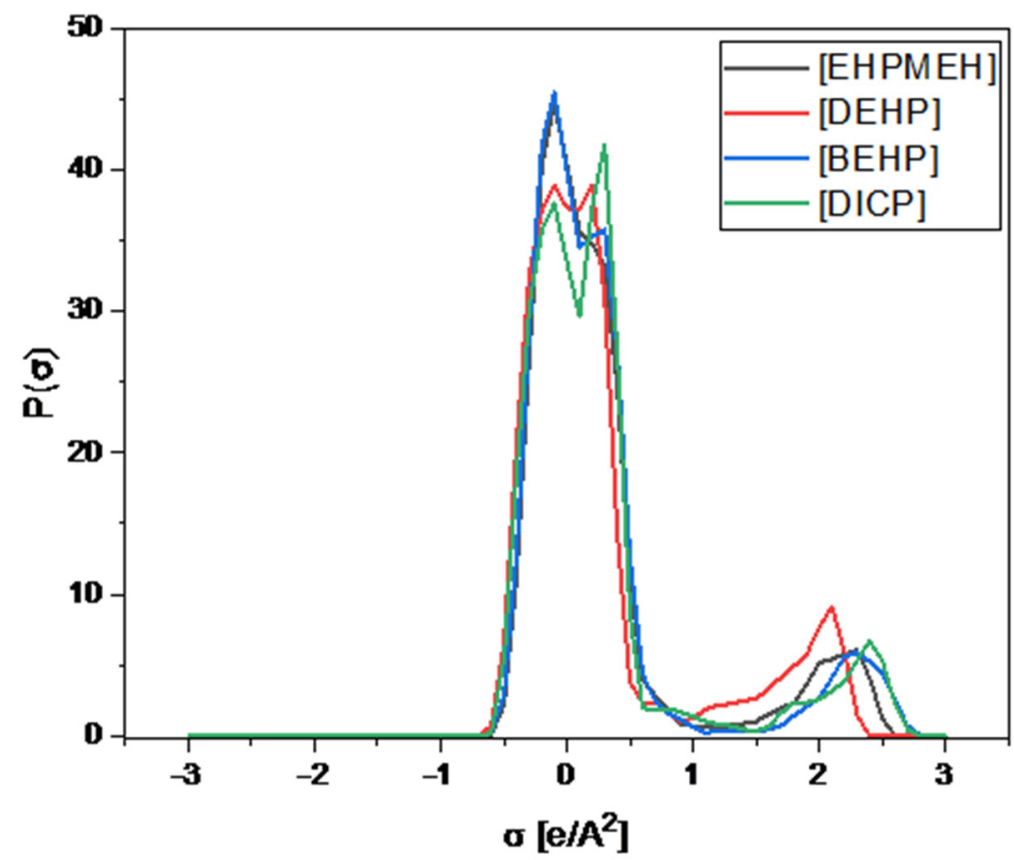

Figure 3. $\sigma$-profile of the anions used in the work of Zhao et al. [23].

Having discussed that, the same effect of the central atoms in the IL cations is observed on the extraction. The change from $\left[\mathrm{N}_{4444}\right]^{+}$to $\left[\mathrm{P}_{4444}\right]^{+}$reduces lithium extraction because the electro drawing character of phosphorus compared with nitrogen produces an increase in the interaction of $\left[\mathrm{P}_{4444}\right]^{+}$with the anion of this cation, thereby decreasing IL dissociation in the aqueous phase and, therefore, the amount of free anion available to extract lithium.

\subsection{Effect of the IL Cation on Extraction and Selectivity}

In the work of Wang et al. [22], lithium, sodium, and magnesium were extracted from the aqueous phase at $\mathrm{pH}=5.0$ using an organic phase that included tributyl phosphate $(\mathrm{TBP})(70 \% v / v), \mathrm{IL}=(10 \% v / v)$, and 1,2-dichloroethane as diluent. Extraction was conducted at $298 \mathrm{~K}$ employing an organic/aqueous ratio of 3:1. The different ILs used are as follows: 1-Butyl pyridinium bis((trifluoromethyl)sulfonyl)imide ([BPy][TF $2 \mathrm{~N}])$; 1-Butyl-1-methylpiperidinium bis((trifluoromethyl)sulfonyl)imide $\left(\left[\mathrm{PP}_{14}\right]\left[\mathrm{TF}_{2} \mathrm{~N}\right]\right)$; 1-Butyl3-methylimidazolium bis((trifluoromethyl)sulfonyl)imide ([BMIm] $\left.\left.\mathrm{TF}_{2} \mathrm{~N}\right]\right)$; and 1-Butyl1-methylpyrrolidinium bis((trifluoromethyl)sulfonyl)imide $\left(\left[\mathrm{P}_{14}\right]\left[\mathrm{TF}_{2} \mathrm{~N}\right]\right)$. The molecular structures used are shown in Figure 4.

According to the literature, lithium is solvated with two bis-(trifluoromethanesulfonyl) amide $\left(\left[\mathrm{TF}_{2} \mathrm{~N}\right]^{-}\right)$anions in the inner shell and the IL cation in the second shell, while the cis- $\left[\mathrm{TF}_{2} \mathrm{~N}\right]^{-}$conformer is more stable than the trans- $\left[\mathrm{TF}_{2} \mathrm{~N}\right]^{-}$conformer acting as a bidentate ligand $[48,49]$. These findings are used to build the complex. A comparison between the experimental and the theoretical calculations is presented in Table 2. COSMORS and experimental data for lithium extraction and $\alpha_{\mathrm{Li}^{+} / \mathrm{Na}^{+}}$are in good agreement in terms of tendencies. 
(a)

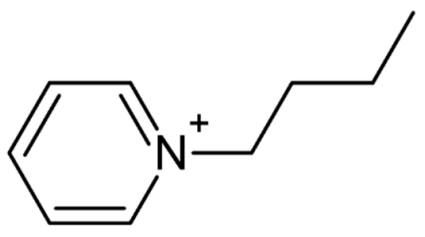

(c)

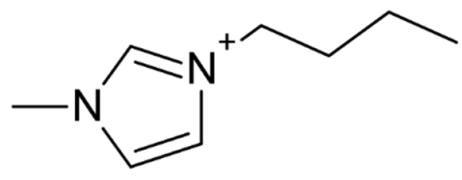

(b)

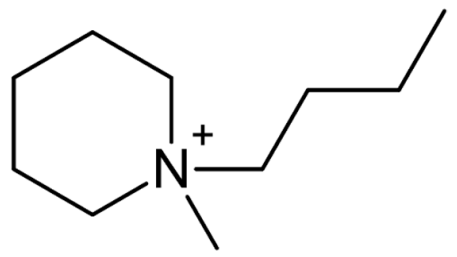

(d)

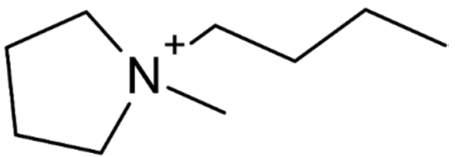

(e)<smiles>O=S(=O)([N-]S(=O)(=O)C(F)(F)F)C(F)(F)F</smiles>

Figure 4. Molecular structure of the cations and anions used (a) $[\mathrm{BPy}]+,(\mathrm{b})\left[\mathrm{PP}_{14}\right]^{+},(\mathrm{c})[\mathrm{BMIm}]+$, (d) and $(\mathbf{e})\left[\mathrm{TF}_{2} \mathrm{~N}\right]^{-}$.

Table 2. Theoretical global extraction constants $\left(\mathrm{K}_{\mathrm{global}}\right)$ and selectivity validation using experimental data [22] for different ILs when TBP is used.

\begin{tabular}{|c|c|c|c|c|c|c|}
\hline IL & $\log \left(\mathrm{K}_{\text {global. }} \mathrm{Li}^{+}\right)$ & $\underset{\mathrm{Li}^{+}}{\% \text { Extraction }}$ & $\begin{array}{l}\text { Theoretical } \\
\log \left(\alpha_{L i^{+} / N a^{+}}\right)\end{array}$ & $\begin{array}{c}\text { Experimental } \\
\alpha_{L^{+} / N a^{+}}\end{array}$ & $\begin{array}{c}\text { Theoretical } \\
\log \left(\alpha_{L i^{+}} / M g^{2+}\right)\end{array}$ & $\begin{array}{c}\text { Experimental } \\
\alpha_{L i^{+} / M g^{2+}}\end{array}$ \\
\hline$[\mathrm{BPy}]\left[\mathrm{TF}_{2} \mathrm{~N}\right]$ & 185.77 & 90.67 & 159.544 & 25.638 & 37.17 & 75.35 \\
\hline$[\mathrm{BMIm}]\left[\mathrm{TF}_{2} \mathrm{~N}\right]$ & 185.29 & 88.23 & 159.545 & 26.299 & 37.65 & 71.43 \\
\hline$\left[\mathrm{P}_{14}\right]\left[\mathrm{TF}_{2} \mathrm{~N}\right]$ & 182.60 & 87.59 & 159.540 & 21.026 & 40.38 & 51.10 \\
\hline$\left[\mathrm{PP}_{14}\right]\left[\mathrm{TF}_{2} \mathrm{~N}\right]$ & 179.71 & 83.76 & 159.542 & 23.129 & 49.57 & 45.26 \\
\hline
\end{tabular}

According to COSMO-RS calculations on hydrophobicity, the following trend is obtained from the most hydrophobic to the most hydrophilic cation: $\left[\mathrm{PP}_{14}\right]^{+}>\left[\mathrm{P}_{14}\right]^{+}>[\mathrm{BMIm}]^{+}>[\mathrm{BPy}]^{+}$. When the hydrophobicity of IL decreases, there will be more IL distributed in the aqueous phase and, thus, more IL anions available to bond lithium, sodium, and magnesium. In addition, the increase in the ionic dissociation of ILs results in an increase in the number of anions available for extraction. According to data on $\left[\mathrm{TF}_{2} \mathrm{~N}\right]^{-}$based ILs, the ionic dissociations depicted in parentheses are the following: $[\mathrm{Bpy}]^{+}(0.66),[\mathrm{Bmim}]^{+}(0.60)$, and $[\mathrm{P} 14]^{+}(0.5)[50]$. Their dissociation values show a direct relationship in both the degree of dissociation and extraction.

In the case of the trends for magnesium extractions, there is no relationship between theoretical calculations and experimental data. Some differences may occur due to the different solvation by the ILs towards the metals, where it is shown that a higher number of ILs is directly coordinated to lithium [48,49]. Therefore, the same phenomena could be occurring with magnesium, which means that other parallel extraction mechanisms have not been considered in this work. This effect could be more pronounced due to the divalent charge; thus, there would be more solvating IL species around $\mathrm{Mg}^{+2}$.

An interesting point to note is that, when comparing theoretical results from Tables 1 and 2, values differ from each other. This is because both systems are different in that the first one used an IL in an organic solvent and the second one added a synergistic agent. Small amounts of TBP would cause large changes in metal extraction in both experimental results and theoretical calculations. This is attributed to the ability of TBP to displace water molecules, which solvate lithium ion and enhance extraction, as reported for the extraction of other metal ions $[14,51,52]$. However, this was not considered in quantum chemical calculations since no reports were found on the final chemical structure that could be obtained when using TBP for the extraction of lithium; specifically, the number of water molecules surrounding lithium after extraction. The number of water molecules is also necessary for calculations without TBP, which are also not available in literature. 
It is important to say that, in the work of Wang et al. [22], the organic-to-aqueous $(\mathrm{O} / \mathrm{A})$ ratio, where a 3:1 $(\mathrm{O} / \mathrm{A})$, was used instead of the 1:1 O/A ratio employed in Table 1 , which increases metal extractions. This ratio cannot be incorporated into quantum chemical calculations; therefore, is another source of differences in $\log \left(\mathrm{K}_{\text {global. }} \mathrm{Li}^{+}\right)$between tables.

Although the correlations between the experimental and theoretical $\alpha_{\mathrm{Li}^{+} / \mathrm{Mg}^{2+}}$ were not satisfactory, there is a relationship between this and $\alpha_{\mathrm{Li}^{+} / \mathrm{Na}}$ because an increase in the extraction of lithium over magnesium also produces a greater separation of $\mathrm{Li}^{+} / \mathrm{Na}^{+}$. Therefore, a proposed IL for $\mathrm{Li}^{+}$extraction will be based on the obtained selectivity of $\mathrm{Li}^{+} / \mathrm{Na}^{+}$. This will represent a practical advantage as quantum chemical calculations on $\mathrm{Na}^{+}$are much faster than on $\mathrm{Mg}^{2+}$, reducing computation time.

\subsection{Proposal of ILs for Selective Extraction of Lithium}

TBP is one of the best neutral extractants that increase the extraction of lithium [53]. TBP produces an intrinsic selectivity toward lithium over magnesium due to the presence of the functional group $\mathrm{P}=\mathrm{O}[9,23]$. When TBP is added as an extractant diluted in 1,2-dichloroethane, a high value of selectivity $\mathrm{Li} / \mathrm{Mg}$ is obtained $\left(\alpha_{\mathrm{Li}_{\mathrm{Mg}} \mathrm{Mg}^{2+}}=241\right)$ [22]. Nevertheless, extraction without ILs produces low extraction percentages. Therefore, a counter anion is necessary to make the complexes more hydrophobic and enhance lithium extraction. In this sense, the proposal of an IL needs to consider all different factors that an IL could offer to the IL extraction process hydrophobicity, the dissociation, and the interaction with the metal.

Figure 5 shows the theoretical $\alpha_{\mathrm{Li}^{+} / \mathrm{Na}}$ calculated by COSMO-RS using different hydrophobic cations that are commercially available [54] while keeping the anion of [Tf $\left.\mathrm{T}_{2}\right]^{-}$. According to the results, an increase in the alkyl chain for all the cations studied will increase selectivity towards lithium. This may be due to an increase in the hydrophobicity of IL and a subsequent better interaction of the lithium complex with a less polar organic phase. Among the groups studied, phosphonium-based cations exhibit the best selectivities, which have already been reported in the literature as cations used to enhance extraction or selectivity [10].

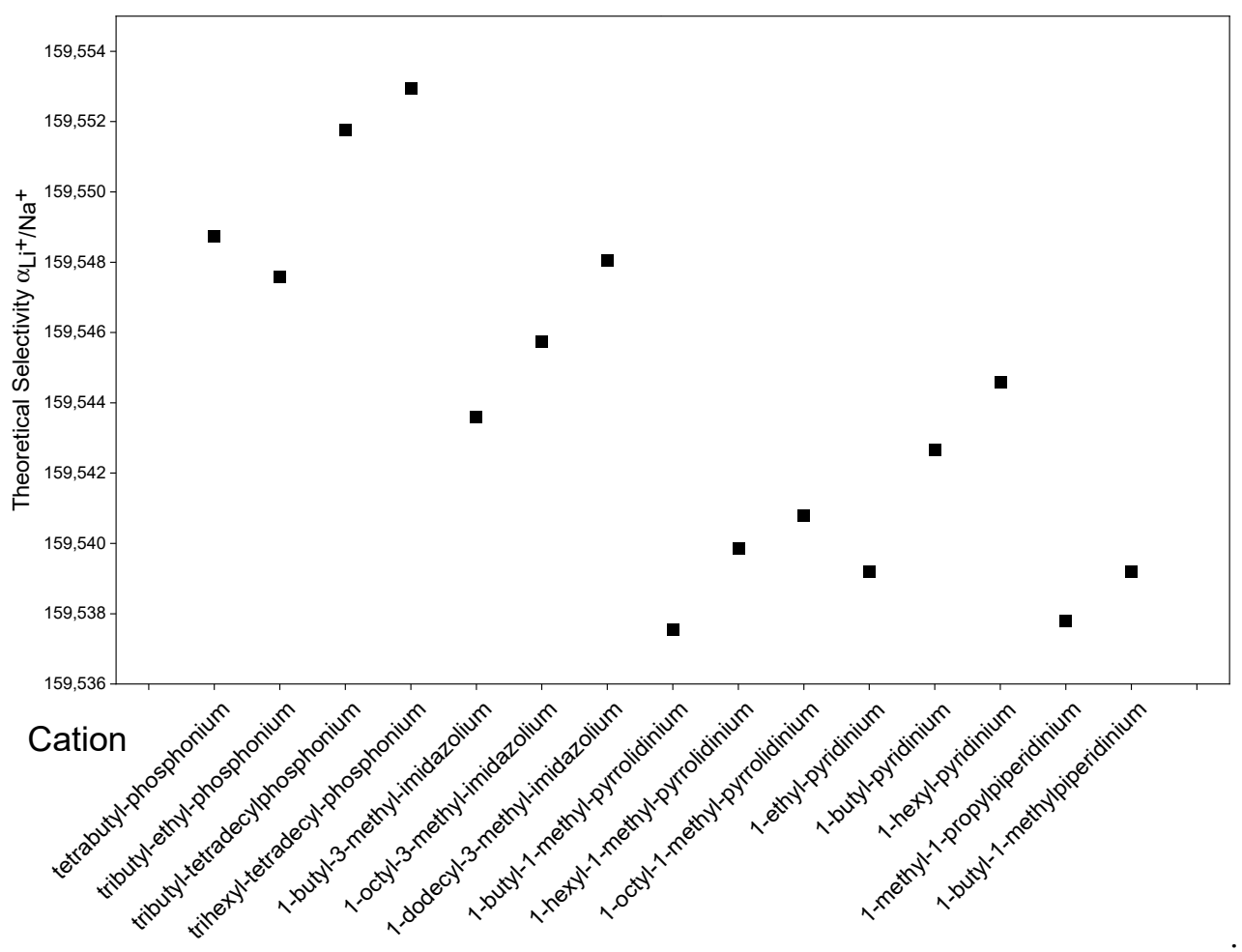

Figure 5. Effect of the cation in $\left[\mathrm{TF}_{2} \mathrm{~N}\right]^{-}$based ILs on the $\alpha_{\mathrm{Li}^{+} / \mathrm{Na}^{+}}$calculated by COSMO-RS. 


\section{Conclusions}

A theoretical model was developed to calculate selectivities in the SX of lithium over sodium and magnesium from brines using COSMO-RS.

The developed model was first validated using experimental data of lithium extraction from brines. Thus, theoretical calculations showed acceptable agreements with experimental data and were able to predict trends.

The main factors that improve selectivity in lithium extractions are the $\mathrm{P}=\mathrm{O}$ functional groups in the anion and IL dissociation, which is directly related to the chemical structure of the cation and anion. Additionally, the use of TBP as extraction enhancer can significantly improve selectivity.

Finally, an IL has been proposed to improve selectivity considering all the previously mentioned findings. Thus, IL trihexyl tetradecyl phosphonium bis(trifluoromethylsulfonyl) imide, $\left[\mathrm{P}_{66614}\right]\left[\mathrm{Tf}_{2} \mathrm{n}\right]$, is recommended for enhancing the selective extraction of lithium from brines.

This work opens possibilities for the application of ILs in the SX of lithium from brines, avoiding long processing times and large water consumption.

Author Contributions: Conceptualization, F.O.; methodology, F.O.; software, G.D. (Guillermo Durán) and E.V.; validation, F.O. and G.D. (Guillermo Durán); formal analysis, F.O. and E.Q.-M.; investigation, G.D. (Guillermo Durán); data curation, E.V. and C.A.-L.; writing-original draft preparation, G.D. (Georgina Díaz), R.C. and G.M.; writing-review and editing, G.D. (Georgina Díaz) and J.R.; visualization, C.A.-L.; project administration, E.Q.-M.; funding acquisition, E.Q.-M. All authors have read and agreed to the published version of the manuscript.

Funding: This research was funded by Project FONDECYT REGULAR N ${ }^{\circ} 1211234$ from National Agency for Research and Development (ANID), Project DICYT Asociativo 091711QM_DAS from University of Santiago de Chile and the Scholarship Program DOCTORADO NACIONAL/2019_ 21191785 (ANID).

Data Availability Statement: Not applicable.

Conflicts of Interest: The authors declare no conflict of interest.

\section{References}

1. Li, H.; Li, H.; Liang, J.; Yan, H.; Cai, Z. Study on the Synergistic Extraction of Lithium from Spent Lithium Cobalt Oxide Batteries by Molten Salt Electrolysis and Two-Step Precipitation Method. Crystals 2021, 11, 1163. [CrossRef]

2. Waengwan, P.; Eksangsri, T. Recovery of Lithium from Simulated Secondary Resources $\left(\mathrm{LiCO}_{3}\right)$ through Solvent Extraction. Sustainability 2020, 12, 7179. [CrossRef]

3. Hoshino, T. Preliminary studies of lithium recovery technology from seawater by electrodialysis using ionic liquid membrane. Desalination 2013, 317, 11-16. [CrossRef]

4. Xu, W.; Liu, D.; He, L.; Zhao, Z. A Comprehensive Membrane Process for Preparing Lithium Carbonate from High Mg/Li Brine. Membranes 2020, 10, 371. [CrossRef]

5. Liu, G.; Zhao, Z.; Ghahreman, A. Novel approaches for lithium extraction from salt-lake brines: A review. Hydrometallurgy 2019, 187, 81-100. [CrossRef]

6. Stringfellow, W.T.; Dobson, P.F. Technology for the Recovery of Lithium from Geothermal Brines. Energies 2021, $14,6805$. [CrossRef]

7. Sun, X.; Hao, H.; Zhao, F.; Liu, Z. Tracing global lithium flow: A trade-linked material flow analysis. Resour. Conserv. Recycl. 2017, 124, 50-61. [CrossRef]

8. Graham, J.D.; Rupp, J.A.; Brungard, E. Lithium in the Green Energy Transition: The Quest for Both Sustainability and Security. Sustainability 2021, 13, 11274. [CrossRef]

9. Wang, Y.; Liu, H.; Fan, J.; Liu, X.; Hu, Y.; Hu, Y.; Zhou, Z.; Ren, Z. Recovery of Lithium Ions from Salt Lake Brine with a High Magnesium/Lithium Ratio Using Heteropolyacid Ionic Liquid. ACS Sustain. Chem. Eng. 2018, 7, 3062-3072. [CrossRef]

10. Mishra, B.B.; Devi, N. Solvent extraction and separation of europium (III) using a phosphonium ionic liquid and an organophosphorus extractant-A comparative study. J. Mol. Liq. 2018, 271, 389-396. [CrossRef]

11. Zante, G.; Masmoudi, A.; Barillon, R.; Trébouet, D.; Boltoeva, M. Separation of lithium, cobalt and nickel from spent lithium-ion batteries using TBP and imidazolium-based ionic liquids. J. Ind. Eng. Chem. 2020, 82, 269-277. [CrossRef]

12. Shi, C.; Duan, D.; Jia, Y.; Jing, Y. A highly efficient solvent system containing ionic liquid in tributyl phosphate for lithium ion extraction. J. Mol. Liq. 2014, 200, 191-195. [CrossRef] 
13. Gao, D.; Yu, X.; Guo, Y.; Wang, S.; Liu, M.; Deng, T.; Chen, Y.; Belzile, N. Extraction of lithium from salt lake brine with triisobutyl phosphate in ionic liquid and kerosene. Chem. Res. Chin. Univ. 2015, 31, 621-626. [CrossRef]

14. Zhang, L.; Shi, D.; Li, L.; Peng, X.; Song, F.; Rui, H. Solvent extraction of lithium from ammoniacal solution using thenoyltrifluoroacetone and neutral ligands. J. Mol. Liq. 2019, 274, 746-751. [CrossRef]

15. Zhou, Z.; Liang, S.; Qin, W.; Fei, W. Extraction Equilibria of Lithium with Tributyl Phosphate, Diisobutyl Ketone, Acetophenone, Methyl Isobutyl Ketone, and 2-Heptanone in Kerosene and $\mathrm{FeCl}_{3}$. Ind. Eng. Chem. Res. 2013, 52, 7912-7917. [CrossRef]

16. Zhang, L.; Li, L.; Shi, D.; Peng, X.; Song, F.; Nie, F.; Han, W. Recovery of lithium from alkaline brine by solvent extraction with $\beta$-diketone. Hydrometallurgy 2018, 175, 35-42. [CrossRef]

17. Nguyen, T.H.; Lee, M.S. A Review on the Separation of Lithium Ion from Leach Liquors of Primary and Secondary Resources by Solvent Extraction with Commercial Extractants. Processes 2018, 6, 55. [CrossRef]

18. Pranolo, Y.; Zhu, Z.; Cheng, C.Y. Separation of lithium from sodium in chloride solutions using SSX systems with LIX 54 and Cyanex 923. Hydrometallurgy 2015, 154, 33-39. [CrossRef]

19. Shi, C.; Jing, Y.; Xiao, J.; Wang, X.; Yao, Y.; Jia, Y. Solvent extraction of lithium from aqueous solution using non-fluorinated functionalized ionic liquids as extraction agents. Sep. Purif. Technol. 2017, 172, 473-479. [CrossRef]

20. Li, Z.; Mercken, J.; Li, X.; Riaño, S.; Binnemans, K. Efficient and Sustainable Removal of Magnesium from Brines for Lithium/Magnesium Separation Using Binary Extractants. ACS Sustain. Chem. Eng. 2019, 7, 19225-19234. [CrossRef]

21. Bai, R.; Wang, J.; Wang, D.; Zhang, Y.; Cui, J. Selective separation of lithium from the high magnesium brine by the extraction system containing phosphate-based ionic liquids. Sep. Purif. Technol. 2021, 274, 119051. [CrossRef]

22. Wang, X.; Jing, Y.; Liu, H.; Yao, Y.; Shi, C.; Xiao, J.; Wang, S.; Jia, Y. Extraction of lithium from salt lake brines by bis[(trifluoromethyl)sulfonyl]imide-based ionic liquids. Chem. Phys. Lett. 2018, 707, 8-12. [CrossRef]

23. Zhao, X.; Wu, H.; Duan, M.; Hao, X.; Yang, Q.; Zhang, Q.; Huang, X. Liquid-liquid extraction of lithium from aqueous solution using novel ionic liquid extractants via COSMO-RS and experiments. Fluid Phase Equilibria 2018, 459, 129-137. [CrossRef]

24. Klamt, A.; Eckert, F. COSMO-RS: A novel and efficient method for the a priori prediction of thermophysical data of liquids. Fluid Phase Equilibria 2000, 172, 43-72. [CrossRef]

25. Ali, S.M.; Pahan, S.; Bhattacharyya, A.; Mohapatra, P.K. Complexation thermodynamics of diglycolamide with f-elements: Solvent extraction and density functional theory analysis. Phys. Chem. Chem. Phys. 2016, 18, 9816-9828. [CrossRef] [PubMed]

26. Hu, F.; Hu, H.; Yang, J.; Luo, Y.; Lundstrom, M.; Ji, G.; Hu, J. Preferential extraction of Ni(II) over Co(II) by arylsulphonic acid in the presence of pyridinecarboxylate ester: Experimental and DFT calculations. J. Mol. Liq. 2019, 291, 111253. [CrossRef]

27. Pahan, S.; Boda, A.; Ali, S.M. Density functional theoretical analysis of structure, bonding, interaction and thermodynamic selectivity of hexavalent uranium $\left(\mathrm{UO}_{2}{ }^{2+}\right)$ and tetravalent plutonium $\left(\mathrm{Pu}^{4+}\right)$ ion complexes of tetramethyl diglycolamide (TMDGA). Theor. Chim. Acta 2015, 134, 41. [CrossRef]

28. Olea, F.; Rosales, G.; Quintriqueo, A.; Romero, J.; Pizarro, J.; Ortiz, C.; Quijada-Maldonado, E. Theoretical prediction of selectivity in solvent extraction of $\mathrm{La}(\mathrm{III})$ and $\mathrm{Ce}(\mathrm{III})$ from aqueous solutions using $\beta$-diketones as extractants and kerosene and two imidazolium-based ionic liquids as diluents via quantum chemistry and COSMO-RS calculations. J. Mol. Liq. 2021, 325, 114655. [CrossRef]

29. Shi, C.; Jing, Y.; Xiao, J.; Wang, X.; Jia, Y. Liquid-liquid extraction of lithium using novel phosphonium ionic liquid as an extractant. Hydrometallurgy 2017, 169, 314-320. [CrossRef]

30. Shi, C.; Jing, Y.; Jia, Y. Solvent extraction of lithium ions by tri-n-butyl phosphate using a room temperature ionic liquid. J. Mol. Liq. 2016, 215, 640-646. [CrossRef]

31. Gao, D.; Guo, Y.; Yu, X.; Wang, S.; Deng, T. Extracting Lithium from the High Concentration Ratio of Magnesium and Lithium Brine Using Imidazolium-Based Ionic Liquids with Varying Alkyl Chain Lengths. J. Chem. Eng. Jpn. 2016, 49, 104-110. [CrossRef]

32. Zhou, W.; Li, Z.; Xu, S. Extraction of Lithium from Magnesium-Rich Solution Using Tri-n-butyl Phosphate and Sodium Hexafluorophosphate. J. Sustain. Met. 2021, 7, 1368-1378. [CrossRef]

33. Haynes, W. Handbook of Chemistry and Physics; CRC Press: Boca Raton, FL, USA, 2017; p. 12.

34. Brown, I.D. What factors determine cation coordination numbers? Acta Crystallogr. Sect. B Struct. Sci. 1988, 44, 545-553. [CrossRef]

35. Giffin, G.A.; Moretti, A.; Jeong, S.; Passerini, S. Complex Nature of Ionic Coordination in Magnesium Ionic Liquid-Based Electrolytes: Solvates with Mobile $\mathrm{Mg}^{2+}$ Cations. J. Phys. Chem. C 2014, 118, 9966-9973. [CrossRef]

36. Li, Z.; Binnemans, K. Opposite selectivities of tri- $\mathrm{n}$-butyl phosphate and Cyanex 923 in solvent extraction of lithium and magnesium. AIChE J. 2021, 67, e17219. [CrossRef]

37. Masmoudi, A.; Zante, G.; Trébouet, D.; Barillon, R.; Boltoeva, M. Understanding the Mechanism of Lithium Ion Extraction Using Tributyl Phosphate in Room Temperature Ionic Liquid. Solvent Extr. Ion Exch. 2020, 38, 777-799. [CrossRef]

38. Weigend, F.; Ahlrichs, R. Balanced basis sets of split valence, triple zeta valence and quadruple zeta valence quality for $H$ to $R n$ : Design and assessment of accuracy. Phys. Chem. Chem. Phys. 2005, 7, 3297-3305. [CrossRef]

39. Jana, G.; Jha, R.; Pan, S.; Chattaraj, P.K. Microsolvation of lithium-phosphorus double helix: A DFT study. Theor. Chim. Acta 2019, 138, 75. [CrossRef]

40. Ganesamoorthy, C.; Wölper, C.; Nizovtsev, A.S.; Schulz, S. Synthesis and Structural Characterization of Magnesium-Substituted Polystibides [(LMg $\left.)_{4} \mathrm{Sb}_{8}\right]$. Angew. Chem. Int. Ed. 2016, 55, 4204-4209. [CrossRef]

41. Nhung, N.T.A. Quantum Chemical Assessment of Magnesium Hydride Complexes with Bistriphenylphosphine of Group 14 Elements $\left[\mathrm{H}_{2} \mathrm{Mg}-\left\{\mathrm{E}\left(\mathrm{PPh}_{3}\right)_{2}\right\}\right](\mathrm{E}=\mathrm{C}$ to $\mathrm{Pb})$. Vietnam J. Chem. 2018, 56, 445-451. 
42. Arrowsmith, M.; Auerhammer, D.; Bertermann, R.; Braunschweig, H.; Celik, M.A.; Erdmannsdörfer, J.; Krummenacher, I.; Kupfer, T. From Borane to Borylene without Reduction: Ambiphilic Behavior of a Monovalent Silylisonitrile Boron Species. Angew. Chem. Int. Ed. 2017, 56, 11263-11267. [CrossRef] [PubMed]

43. Perdew, J.P. Density-functional approximation for the correlation energy of the inhomogeneous electron gas. Phys. Rev. B 1986, 33, 8822-8824. [CrossRef] [PubMed]

44. Caldeweyher, E.; Mewes, J.-M.; Ehlert, S.; Grimme, S. Extension and evaluation of the D4 London-dispersion model for periodic systems. Phys. Chem. Chem. Phys. 2020, 22, 8499-8512. [CrossRef] [PubMed]

45. Serena software. PCModel V10.0, Molecular Modeling Software; Serena Software: Bloomington, IN, USA, 2004.

46. Smirnov, P.R.; Trostin, V.N. Structure of the nearest surrounding of the Li+ ion in aqueous solutions of its salts. Russ. J. Gen. Chem. 2006, 76, 175-182. [CrossRef]

47. Di Tommaso, D.; de Leeuw, N.H. Structure and dynamics of the hydrated magnesium ion and of the solvated magnesium carbonates: Insights from first principles simulations. Phys. Chem. Chem. Phys. 2010, 12, 894-901. [CrossRef]

48. Umebayashi, Y.; Mori, S.; Fujii, K.; Tsuzuki, S.; Seki, S.; Hayamizu, K.; Ishiguro, S.-I. Raman Spectroscopic Studies and Ab Initio Calculations on Conformational Isomerism of 1-Butyl-3-methylimidazolium Bis-(trifluoromethanesulfonyl)amide Solvated to a Lithium Ion in Ionic Liquids: Effects of the Second Solvation Sphere of the Lithium Ion. J. Phys. Chem. B 2010, 114, 6513-6521. [CrossRef]

49. Fujii, K.; Hamano, H.; Doi, H.; Song, X.; Tsuzuki, S.; Hayamizu, K.; Seki, S.; Kameda, Y.; Dokko, K.; Watanabe, M.; et al. Unusual Li+Ion Solvation Structure in Bis(fluorosulfonyl)amide Based Ionic Liquid. J. Phys. Chem. C 2013, 117, 19314-19324. [CrossRef]

50. Nordness, O.; Brennecke, J.F. Ion Dissociation in Ionic Liquids and Ionic Liquid Solutions. Chem. Rev. 2020, 120, 12873-12902. [CrossRef]

51. Kameta, N.; Imura, H. Effect of Tris(acetylacetonato)chromium(III) as a Complex Ligand on the Extraction of Lanthanoid(III) with 2-Thenoyltrifluoroacetone. Bull. Chem. Soc. Jpn. 2001, 74, 1641-1647. [CrossRef]

52. Imura, H.; Ebisawa, M.; Kato, M.; Ohashi, K. Novel synergism by complex ligands in solvent extraction of rare earth metals(III) with $\beta$-diketones. J. Alloy. Compd. 2006, 408-412, 952-957. [CrossRef]

53. Li, R.; Wang, W.; Wang, Y.; Wei, X.; Cai, Z.; Zhou, Z. Novel ionic liquid as co-extractant for selective extraction of lithium ions from salt lake brines with high Mg/Li ratio. Sep. Purif. Technol. 2021, 277, 119471. [CrossRef]

54. Olea, F.; Merlet, G.; Araya-López, C.; Cabezas, R.; Villarroel, E.; Quijada-Maldonado, E.; Romero, J. Separation of vanillin by perstraction using hydrophobic ionic liquids as extractant phase: Analysis of mass transfer and screening of ILs via COSMO-RS. Sep. Purif. Technol. 2021, 274, 119008. [CrossRef] 